\title{
Beitrag zur Problematik kleinzelliger Carcinome
}

\author{
J. Cunderlík und E. Pozdechová \\ Landeskrankenhaus für die Tuberkulose in Podunajské Biskupice \\ (Direktor: Doz. Dr. K. VIRsík)
}

Eingegangen am 19. Dezember 1966

In den Jahren 1955-1966 wurden 290 Fälle von Lungencarcinom in unserer Anstalt behandelt; 128 waren bioptisch verifiziert $(44,9 \%)$. In dieser Gruppe wurde eine Serie von 14 Fällen $(10,9 \%$ ) als kleinzellige Tumoren bestätigt. Wir fanden, daß dieser Typ des Lungenkrebses eine außergewöhnlich schlechte Prognose, rasches Wachstum, sehr frühe Metastasenbildung, raschen Verlauf und geringe Aussicht auf chirurgische Behandlung hat. Das klinische Bild des kleinzelligen Carcinoms unterschied sich im wesentlichen nicht vom klinischen Bild der anderen Lungencarcinomtypen. Die geringe Anzahl der Fälle erlaubt keine Stellungnahme in bezug auf die konservative Behandlung.

J. CunderLf́K

Landeskrankenhaus für die Tuberkulose

Podunajské Biskupice/ČSSR 